\title{
Plasma Escherichia Coli $\beta$-Galactosidase as a Marker of Tumor Burden and Response to Experimental Anti-Neoplastic Therapy in Nude Mice Xenografted with lacZ Transduced Human Tumor Cells
}

\author{
Claus Holst-Hansen, Ross Wentworth Stephens, Bente Egholm Johannessen, Peter \\ Buhl Jensen and Nils Brünner \\ The Finsen Laboratory (CHH, RWS, BEJ, NB), The Laboratory of Experimental Medical Oncology (PBJ), The Finsen \\ Center, Copenhagen University Hospital, Denmark
}

\begin{abstract}
SUMMARY: Genetic labeling of tumor cells with the Escherichia coli lacZ reporter gene, encoding the enzyme $\beta$-galactosidase, is widely used for histochemical detection of micrometastases in mice. Recently, we have developed a novel, highly sensitive and specific immunocapture chemiluminescence assay for the quantitation of $E$. coli $\beta$-galactosidase. This assay achieved a detection limit of $0.01 \mathrm{mU}$ of $E$. coli $\beta$-galactosidase per milliliter, and $97 \%$ signal recovery of purified enzyme added to mouse plasma. LacZ transduced MDA-MB-231 BAG human breast cancer cells grown in vitro released soluble $\beta$-galactosidase into the culture medium, and the concentration found correlated with cell density. Growth of the same cells in nude mice produced readily measurable levels of $E$. coli $\beta$-galactosidase enzyme activity in host plasma and a highly significant correlation could be demonstrated between the size of primary tumor xenografts and the host plasma level of $E$. coli $\beta$-galactosidase activity. When mice bearing MDA-MB-231 BAG tumor xenografts were treated intravenously with a single injection of doxorubicin $(5 \mathrm{mg} / \mathrm{kg})$, the mean tumor volume after 16 days was reduced 4-fold in the group of doxorubicin-treated mice compared with saline-treated control mice, and the mean level of plasma $E$. coli $\beta$-galactosidase was correspondingly reduced 3.8 -fold in the doxorubicintreated mice compared with control mice. Sensitive and specific measurement of soluble $E$. coli $\beta$-galactosidase in blood, using an immunocapture chemiluminescence assay, thus provides objective assessment of tumor burden in mice xenografted with lac $Z$ transduced human tumors. This assay may have important applications as a tool for determining the efficacy of new experimental anti-tumor agents. (Lab Invest 2000, 80:719-724).
\end{abstract}

$M$ ethods for objective quantitation of tumor burden in animals are desirable for experimental tumor studies, including the evaluation of anti-tumor therapy. Tumor burden in mice with subcutaneously growing tumors is usually measured bidimensionally using calipers, but for several orthotopically grown tumors, such as ovarian cancer (Will et al, 1975), pleural cancer (Astoul et al, 1994), ascites tumors (Low et al, 1996), or colon cancer (Pocard et al, 1996), as well as metastatic tumors, this method is not feasible.

Transfection of tumor cell lines with the Escherichia coli lac $Z$ reporter gene, which codes for $\beta$-galactosidase, has often been used as a histochemical marker for detection and quantitation of the disseminated tumor cells (Lin et al, 1990). Thus, $\beta$-galactosidase activity can be detected by staining with the chromogenic substrate 5-bromo-4-chloro-3-indolyl- $\beta$-D-galactopyranoside (Xgal), which results in deposition of an insoluble dark blue reaction product (Brünner et al, 1992). Recently, we have

Received January 27, 2000.

Address reprint requests to: Dr. N. Brünner, The Finsen Laboratory, Copenhagen University Hospital, Strandboulevarden 49, DK-2100 Copenhagen $\varnothing$, Denmark. Fax: 453538 5450; E-mail: nils@finsenlab.dk developed a novel, highly sensitive and specific immunocapture chemiluminescence assay for the quantitation of $E$. coli $\beta$-galactosidase activity in organ extracts of nude mice with lac $Z$ transduced human tumor xenografts (Holst-Hansen et al, 1998).

In this study, we show that cancer cells, transduced with the $E$. coli lacZ reporter gene, release $\beta$-galactosidase into culture media in vitro. When grown in vivo in nude mice these cells release $\beta$-galactosidase into the host circulation. $\beta$-galactosidase activity in host plasma was strongly correlated with tumor volume, and based on an experiment with doxorubicin we propose that this assay can be used to monitor tumor burden in response to experimental anti-tumor therapy.

\section{Results}

Release of $\beta$-Galactosidase Activity from lacZ
Transduced Tumor Cells into Culture Medium

For measurements of conditioned medium, specific recovery of $\beta$-galactosidase activity was first demonstrated by addition of increasing concentrations of purified $E$. coli $\beta$-galactosidase standard to serumfree culture medium (SFM) followed by immunocapture assay of the $\beta$-galactosidase activity. In the SFM, 
$99 \%$ recovery of $\beta$-galactosidase activity was obtained (Fig. 1).

When MDA-MB-231 BAG cells were grown in monolayer culture, it was found that $\beta$-galactosidase activity could readily be measured in the conditioned medium. To test the relationship between cell density and $\beta$-galactosidase activity in conditioned medium, different densities of MDA-MB-231 BAG cells were grown in culture under serum-free conditions for 48 hours, and subsequently the conditioned media were assayed for $\beta$-galactosidase activity. In the range of $10^{3}$ to $10^{6}$ cells per milliliter of medium, cell number correlated significantly with $\beta$-galactosidase activity measured in the conditioned medium (linear correlation coefficient, $r>0.98, p<0.001$, Fig. 2).

In addition, when testing three other lac $Z$ transfected human tumor cell lines, MDA-MB-435 BAG breast carcinoma, PC-3 prostate carcinoma, and MV3 melanoma, which stably expressed the lac $Z$ gene, a linear correlation was observed between $\beta$-galactosidase activity measured in the conditioned medium and cell number ( $r>0.98$ and $p<0.001$ for all three cell lines, data not shown). By comparing standard curves of purified $E$. coli $\beta$-galactosidase in phosphate-buffered saline (PBS) with and without addition of doxorubicin, it was verified that doxorubicin in concentrations up to $2 \mu \mathrm{g} / \mathrm{ml}$ did not interfere with the measurements of $\beta$-galactosidase activity in the immunocapture assay (data not shown).

\section{Recovery of $\beta$-Galactosidase in Mouse Plasma}

For measurements of mouse plasma, specific recovery of $\beta$-galactosidase activity was demonstrated by addition of increasing concentrations of purified $E$. coli $\beta$-galactosidase standard to an undiluted control citrate mouse plasma pool, and subsequent determination of the $\beta$-galactosidase activity by the immunocapture assay. In the plasma pool, 97\% recovery of $\beta$-galactosidase activity was obtained (Fig. 1).

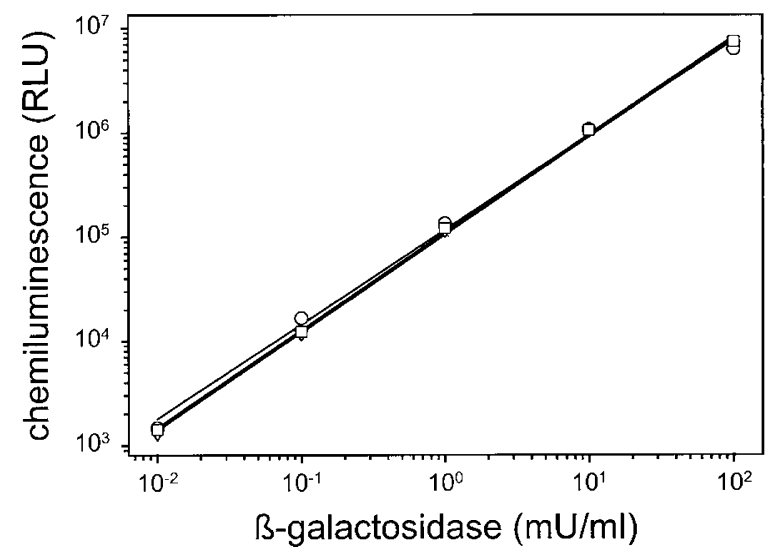

Figure 1.

Standard curve for the chemiluminescence signal from purified $E$. coli $\beta$-galactosidase added at increasing concentrations to phosphate-buffered saline (PBS) $(\nabla)$, and recovery of chemiluminescence signal from purified $E$. coli $\beta$-galactosidase added at increasing concentrations to an undiluted citrate mouse plasma pool $(\bigcirc)$ or serum-free culture medium $(\square)$. Values shown are the mean \pm SEM of triplicates and are displayed as log-log plots. The linear correlation coefficient for each fitted line was $>0.99, p<0.001$.

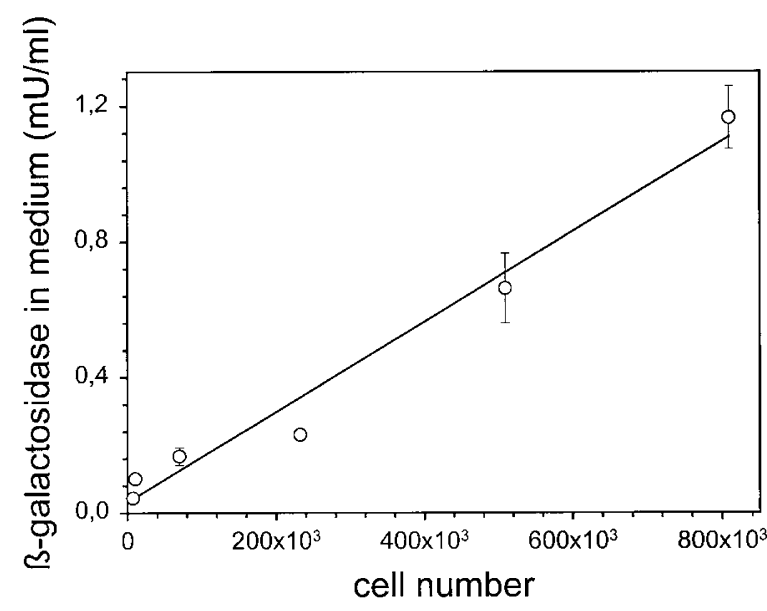

Figure 2.

Release of bacterial $\beta$-galactosidase from MDA-MB-231 BAG cells in vitro. MDA-MB-231 BAG cells were cultured at different densities for 48 hours under serum-free conditions with Eagles MEM containing $0.1 \%$ bovine serum albumin (BSA). Aliquots of culture supernatants were used for the measurements of $\beta$-galactosidase activity. At the end of the experiment, the cell number was determined by the MTT-method. Results are expressed as the mean \pm SEM for three independent determinations. The linear correlation coefficient for the fitted line was $>0.98, p<0.001$.

\section{$\boldsymbol{\beta}$-Galactosidase Activity in Plasma Correlates with Tumor Volume in Mice Xenografted with lacZ Transduced Human Tumor Cells}

Whereas plasma from mice without tumors gave negligible $\beta$-galactosidase signal in the immunocapture assay, significant levels of $E$. coli $\beta$-galactosidase were detected in plasma from mice xenografted with MDA-MB-231 BAG tumor cells. A study on the relationship between $\beta$-galactosidase activity and tumor burden was then performed. Fifty mice were inoculated subcutaneously and bilaterally with MDA-MB231 BAG tumor cells. Tumors were allowed to grow for 4 ( $n=9$ mice), 6 ( $n=10$ mice), and 8 ( $n=31$ mice) weeks. At these different time points, tumor volume was measured and blood was taken for citrate plasma by cardiac puncture under anesthesia. The total tumor volume of the left and the right tumors differed for the individual mice in each group, representing the following mean values and ranges: $120 \mathrm{~mm}^{3}\left(28-250 \mathrm{~mm}^{3}\right.$; 4 weeks of tumor growth); $1830 \mathrm{~mm}^{3}\left(462-3836 \mathrm{~mm}^{3}\right.$; 6 weeks of tumor growth); and $7170 \mathrm{~mm}^{3}$ (1340$22165 \mathrm{~mm}^{3}$; 8 weeks of tumor growth). The individual plasmas (from individual mice) were measured for $\beta$-galactosidase activity. The mean values of plasma $\beta$-galactosidase activity in the three groups was as follows: $0.019 \mathrm{mU} / \mathrm{ml}(0.0070-0.055 \mathrm{mU} / \mathrm{ml}$; 4 weeks of tumor growth); $0.15 \mathrm{mU} / \mathrm{ml}(0.016-0.38 \mathrm{mU} / \mathrm{ml} ; 6$ weeks of tumor growth); and $0.65 \mathrm{mU} / \mathrm{ml}$ (0.0069-3.6 $\mathrm{mU} / \mathrm{ml} ; 8$ weeks of tumor growth). When the individual $\beta$-galactosidase activity levels were plotted against the corresponding total tumor volume per mouse, it was found that the plasma $\beta$-galactosidase activity values correlated well with the corresponding tumor volumes (Spearman correlation coefficient rho $=0.89$, $p<0.001$, Fig. 3). From Figure 3, it can be estimated that the minimum tumor volume in MDA-MB-231 BAG 


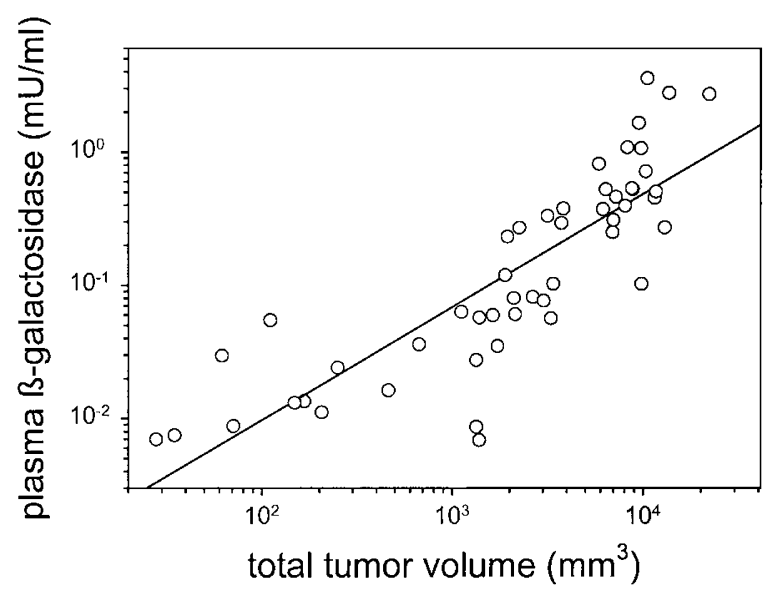

Figure 3 .

Comparison between tumor volume and plasma $\beta$-galactosidase activity level. The $\beta$-galactosidase activity in individual host plasma samples from mice xenografted with MDA-MB-231 BAG tumor cells was plotted against the total tumor volume of the tumors on the left and the right flanks of each mouse. Spearman correlation coefficient rho $=0.89, p<0.001$.

tumor bearing mice, which produces detectable levels of $\beta$-galactosidase activity in plasma, corresponds to approximately $100 \mathrm{~mm}^{3}$ (representing approximately $5 \times 10^{7}-10^{8}$ cells).

In a subsequent experiment the other human breast cancer cell line (MDA-MB-435 BAG) was inoculated subcutaneously and bilaterally into 28 nu/nu-META/ Bom mice, seven mice in each group. Tumors were allowed to grow for 6 weeks (Group 1), 8 weeks (Group 2), 10 weeks (Group 3), and 12 weeks (Group 4). Tumor size was measured every week. At the end of the experiment the total tumor volume of the left and the right tumors represented the following mean values and ranges: $140 \mathrm{~mm}^{3}\left(40-720 \mathrm{~mm}^{3}\right.$; Group 1); $210 \mathrm{~mm}^{3}$ (43-740 mm³; Group 2); $750 \mathrm{~mm}^{3}$ (83-3100 $\mathrm{mm}^{3}$; Group 3); and $1480 \mathrm{~mm}^{3}$ (340-5100 $\mathrm{mm}^{3}$; Group 4). Blood was taken from individual mice and pooled within each group. Citrate plasma was separated from the blood, and plasma $\beta$-galactosidase activity was measured by the immunocapture assay. The mean values for the pooled plasma of $\beta$-galactosidase activity for each group were: 0.038 $\mathrm{mU} / \mathrm{ml}$ (Group 1); $0.24 \mathrm{mU} / \mathrm{ml}$ (Group 2); $0.41 \mathrm{mU} / \mathrm{ml}$ (Group 3); and $1.9 \mathrm{mU} / \mathrm{ml}$ (Group 4). Comparison of the level of $\beta$-galactosidase activity in pooled plasma (plasma from the mice within each group were pooled) and mean tumor volumes (all tumors within a group) at the time of animal sacrifice showed a strong correlation (linear correlation coefficient $r>0.98, p=0.01$, not shown).

\section{Plasma $\beta$-Galactosidase Activity and Tumor Volume in Response to Doxorubicin Treatment}

To select a potent cytotoxic agent, MDA-MB-231 BAG cells were exposed in vitro to the cytotoxic agents BCNU, ara-C, cisplatin, VP-16, and doxorubicin in a clonogenic chemosensitivity assay. The different agents showed the following cytotoxicity, expressed as $\mathrm{LD}_{50}$ values: $\mathrm{BCNU}(1.3 \mu \mathrm{g} / \mathrm{ml})$; ara-C $(0.080 \mu \mathrm{M})$; cisplatin (0.30 $\mu \mathrm{g} / \mathrm{ml})$; VP-16 $(0.15 \mu \mathrm{M})$; and doxorubicin $(0.030 \mu \mathrm{M})$. Subsequently, doxorubicin was chosen for the anti-tumor treatment of mice.

To determine whether plasma $\beta$-galactosidase activity could be used in evaluating the effect of antineoplastic therapy, 33 mice were inoculated subcutaneously and bilaterally with MDA-MB-231 BAG tumor cells. After 3 weeks of established tumor growth (mean tumor volume: $420 \mathrm{~mm}^{3}$ ), mice were randomized to single IV injection treatment of either saline only (vehicle control) or $5 \mathrm{mg} / \mathrm{kg}$ of doxorubicin, corresponding to $25 \%$ of the $L_{10}$ value for doxorubicin in mice. Subsequently, tumor growth was monitored until termination of the experiment at Day 37 after tumor cell inoculation (Fig 4A). A significant inhibition (Mann-Whitney $U$ test, $p<0.001$ ) of tumor volume at Day 37 was observed in the doxorubicin-treated group (mean tumor volume per mouse: $1200 \mathrm{~mm}^{3}$ ) com-

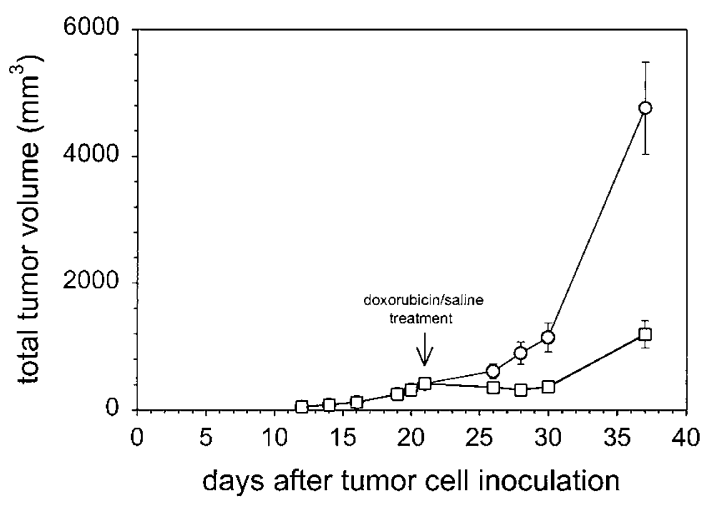

A

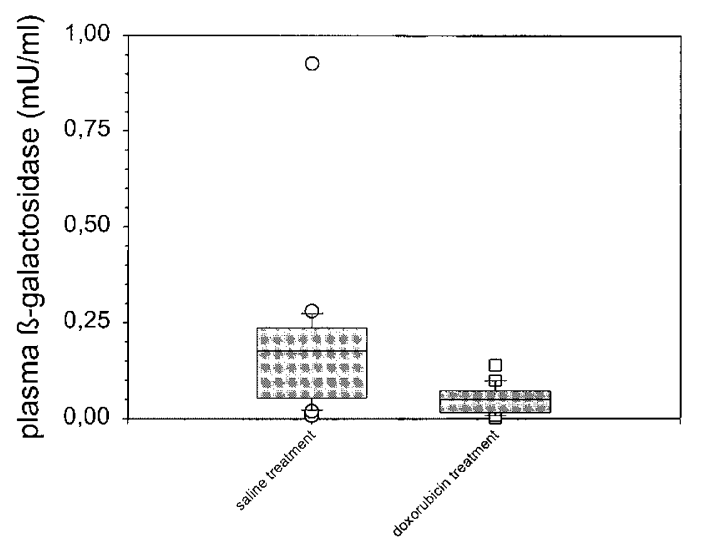

B

Figure 4.

$A$, Tumor volume (total tumor volume of the tumors on the left and the right flanks of all mice) of MDA-MB-231 BAG xenografts in nude mice treated intravenously with a single injection of doxorubicin $(5 \mathrm{mg} / \mathrm{kg})(\square)$ or saline vehicle (O) at Day 21 after cell inoculation. Values shown are mean \pm SEM of 17 mice (saline treated) or 16 mice (doxorubicin treated). At Day 37 the tumor volumes of doxorubicin treated mice were significantly reduced compared with the saline treated mice (Mann-Whitney $U$ test, $p<0.001$ ). $B$, Box plot (showing median, 25th and 75th percentiles) of plasma $\beta$-galactosidase activity level at Day 37, between MDA-MB-231 BAG xenografted nude mice treated with either doxorubicin or saline. A Mann-Whitney $U$ test showed that the doxorubicin treated group had reduced $\beta$-galactosidase plasma levels compared with the group treated with saline alone $(p=0.001)$. 
pared with the control group (mean tumor volume per mouse: $4800 \mathrm{~mm}^{3}$ ), reflecting a 4-fold reduction in mean tumor volume (Fig. 4A). At Day 37 blood samples were drawn and plasma $\beta$-galactosidase activity was determined. A significantly (Mann-Whitney $U$ test, $p=0.001$ ) lower level of plasma $\beta$-galactosidase activity was found in the doxorubicin-treated group (mean $\beta$-galactosidase activity: $0.050 \mathrm{mU} / \mathrm{ml}$ ) compared with the control group (mean $\beta$-galactosidase activity: $0.19 \mathrm{mU} / \mathrm{ml}$ ), reflecting a 3.8 -fold reduction in plasma $\beta$-galactosidase activity (Fig. 4B).

\section{Discussion}

We have previously described the development of a new assay for the measurement of bacterial $\beta$-galactosidase activity in mouse tissue extracts from lac $Z$ transduced human tumor xenografts growing in nude mice, using an immunocapture assay using chemiluminescence detection (Holst-Hansen et al, 1998). This assay provides a high sensitivity, with a detection limit of $0.01 \mathrm{mU} / \mathrm{ml}$ of purified bacterial $\beta$-galactosidase diluted in PBS and a wide dynamic range. In addition, the assay exhibits high specificity for bacterial $\beta$-galactosidase, showing insignificant cross-reactivity with endogenous mammalian lysosomal $\beta$-galactosidase(s). In an experimental metastasis model, this method was well suited for the quantitative determination of the amount of bacterial $\beta$-galactosidase in host mouse lung homogenates, as an estimate of the number of metastatic lac $Z$ transduced tumor cells. In the present study, we report the release in vitro and in vivo of bacterial $\beta$-galactosidase from lac $Z$ transduced human tumor cells, and the correlation of the level of host plasma $E$. coli $\beta$-galactosidase with xenograft tumor volume.

By applying the immunocapture chemiluminescence assay to conditioned media from MDA-MB-231 BAG human breast cancer cells stably transduced with the lac $Z$ reporter gene, it was shown that these cells release soluble $\beta$-galactosidase into the medium. The release of $\beta$-galactosidase was cell number dependent and appeared to be a more general phenomenon, because three other human tumor cell lines stably transfected with the lac $Z$ gene released $\beta$-galactosidase into the culture medium as a linear function of viable cell number. It could be speculated that release of intracellular $\beta$-galactosidase from dying and disintegrating cells contributed significantly to the concentrations measured in the medium. However, this is not considered likely because MTT (3-[4,5dimethyl-thiazol-2-yl]-2,5-diphenyltetrazolium bromide) assays showed that the cultured cells remained viable throughout the monitoring period.

In contrast to nontumor bearing animals, plasma from nude mice with the MDA-MB-231 BAG or MDAMB-435 BAG tumors tested positive for bacterial $\beta$-galactosidase activity. A statistically significant correlation was found between tumor volume and the level of $\beta$-galactosidase activity in mouse plasma, indicating that plasma levels of $\beta$-galactosidase activity reflect tumor burden in the host mice. This may prove to be a methodological improvement for the estimation of tumor burden in animal models, especially when the tumor cells are growing nonsubcutaneously, eg, orthotopically (Hoffman, 1994), and may as such present a significant advantage over currently used methods, eg, area and volume tumor measurements, histological quantitation of tumor cells, and measurements of specific tumor markers. The application of this new assay is further supported by our previous characterization of a close correlation between $\beta$-galactosidase activity in lung tumor extracts and experimental lung metastases (Holst-Hansen et al, 1998).

A study in nude mice was then undertaken to assess whether measurements of $\beta$-galactosidase activity in plasma were responsive to reduction in tumor volume brought about by cytotoxic drug therapy. Mice bearing established MDA-MB-231 BAG tumor xenografts were treated intravenously with a single injection of doxorubicin, which produced a strong inhibition of primary tumor growth compared with saline treatment. It was found that the mean tumor volume and mean plasma $\beta$-galactosidase in doxorubicin treated mice were significantly reduced by 4 - and 3.8 -fold, respectively, compared with vehicle treated mice. These results provide evidence that the plasma level of $\beta$-galactosidase in host mice is an indicator of tumor burden, and furthermore that it reflects response to reduction in tumor burden following cytotoxic drug therapy.

Taken together, soluble $\beta$-galactosidase released from lac $Z$ transduced tumor cells is measurable both in conditioned medium in vitro and in plasma from mice bearing tumor xenografts, using a sensitive immunocapture chemiluminescence assay. Furthermore, plasma levels of $\beta$-galactosidase reflect tumor burden in host mice and are useful as an objective indicator of the response to experimental antineoplastic therapy. This provides, in addition to the histochemical detection of metastatic cells in mice, a new application of the lac $Z$ reporter gene transduced into tumor cell lines.

\section{Materials and Methods}

\section{$\beta$-Galactosidase Assay}

White microwell plates (Berthold, Bad Wildbad, Germany) were coated for 16 hours at $4^{\circ} \mathrm{C}$ with 200 $\mu \mathrm{l} /$ well of the murine monoclonal antibody to $E$. coli $\beta$-galactosidase clone 5B88 (Life Technologies, Gaithersburg, Maryland; $2.5 \mu \mathrm{g} \mathrm{lgG} / \mathrm{ml}$ ) in $0.1 \mathrm{M}$ carbonate buffer, pH 9.5 (Holst-Hansen et al, 1998). Before use, the assay wells were rinsed once with $200 \mu \mathrm{l} /$ well of SuperBlock solution (Pierce Chemicals, Rockford, Illinois) diluted 1:1 with PBS, followed by 3 washes with PBS containing $1 \mathrm{mg} / \mathrm{ml}$ Tween 20 . Wells were then incubated for 1 hour at $37^{\circ} \mathrm{C}$ with $200 \mu \mathrm{l} /$ well in duplicate or triplicate of undiluted samples of conditioned medium or mouse citrate plasma (see below). After $\beta$-galactosidase binding, the wells were washed three times with PBS containing $1 \mathrm{mg} / \mathrm{ml}$ Tween 20, then treated for 45 minutes at $37^{\circ} \mathrm{C}$ with $200 \mu \mathrm{l} /$ well of 
Galacto-Light Reaction Buffer Diluent with GalactonPlus chemiluminescent substrate, according to the instructions from the supplier (Tropix, Bedford, Massachusetts). After the enzymatic cleavage of the substrate, chemiluminescent light emission was triggered by adding automatically $100 \mu \mathrm{l} /$ well of the alkaline polymeric enhancer (Accelerator-II, Tropix), using the pump incorporated in the luminometer (Berthold LB 96 P-2 MicroLumat). Chemiluminescence intensity was measured over a 5 seconds interval with a delay time of 2 seconds.

To define assay sensitivity, the chemiluminescence signal of purified E. coli $\beta$-galactosidase (Grade VIII, 600-1200 U/mg protein, Sigma Chemical, St. Louis, Missouri) diluted in either PBS, culture medium, or mouse citrate plasma was compared with background chemiluminescence signal from PBS, culture medium, or mouse plasma alone. The assay detection limit was defined at a $\mathrm{S} / \mathrm{N}$ ratio of 2 compared with buffer/ plasma control value.

For standardization of the assay, serial dilutions of purified E. coli $\beta$-galactosidase were made in PBS, starting from $100 \mathrm{mU} / \mathrm{ml}$, and then diluted 10-fold down to $0.01 \mathrm{mU} / \mathrm{ml}$. In addition, purified $E$. coli $\beta$-galactosidase was added in different concentrations to either culture medium or an undiluted mouse citrate plasma pool for determination of specific recovery, compared with $E$. coli $\beta$-galactosidase diluted in PBS.

\section{Cell Lines}

The human breast cancer cell lines MDA-MB-231 and MDA-MB 435 were transduced with the BAG vector (Brünner et al, 1992), which consists of the lacZ gene under the transcriptional control of the Moloney murine leukemia long terminal repeat (LTR) promotor and the SV40-promoted neo gene (Price et al, 1987). The lacZ gene encodes the enzyme $E$. coli $\beta$-galactosidase. The transduced cell lines have BAG as a suffix. The cells were routinely propagated in Eagles MEM with Glutamax-1 (Life Technologies) and supplemented with $5 \%$ fetal calf serum (FCS). The human prostate cancer cell line PC-3 and the human melanoma cell line MV3 were transfected with a pRSV/ lacZ/neo construct (Lin et al, 1990) (kindly provided by Dr L. A. Culp), using Lipofectin Reagent (Gibco, Gaithersburg, Maryland) according to the manufacturer's instructions and followed by antibiotic G418 selection and cloning. The lac $Z$ transfected MV3 cells were propagated in DMEM with Glutamax-1 (Life Technologies) and supplemented with $5 \%$ FCS, and the lacZ transfected PC-3 cells were propagated in HAMs (Nutrient mixture Ham's F-12 with Glutamax-1) culture medium (Life Technologies) supplemented with $5 \%$ FCS. All cell lines were tested for and found to be free of mycoplasma contamination.

For collection of conditioned medium, cells were harvested with trypsin/EDTA and added to 24 well cluster plates at different cell densities. On the next day the adherent monolayers were washed twice in PBS and the medium ( $1 \mathrm{ml} /$ well) was changed to serum-free conditions using $0.1 \%$ bovine serum albumin (BSA; Fraction V, Sigma) and $5 \mathrm{~mm}$ HEPES in Eagle's MEM with Glutamax-1 (SFM). Cells were incubated at $37^{\circ} \mathrm{C}$ for 48 hours or as indicated. Conditioned media were collected and centrifuged at 10,000 $\times g$ for 5 minutes at $4^{\circ} \mathrm{C}$, and the supernatants were assayed for $\beta$-galactosidase activity. Cells were quantitated by the MTT-method as described previously (Holst-Hansen et al, 1996).

\section{In Vitro Clonogenic Assay}

Single-cell suspensions of MDA-MB-231 BAG cells $\left(3-4 \times 10^{4}\right.$ cells $\left./ \mathrm{ml}\right)$ in RPMI 1640 supplemented with $10 \%$ fetal calf serum were plated in soft agar on a feeder layer containing sheep red blood cells (Roed et al, 1987) in $35 \mathrm{~mm}$ petri dishes with the indicated drug concentrations (continuous incubation) with the cytotoxic agents carmustine (BCNU) $(0.2-1.5 \mu \mathrm{g} / \mathrm{ml})$, cytosine arabinoside (ara-C) $(0.025-0.15 \mu \mathrm{M})$, cisplatin (0.1-0.4 $\mu \mathrm{g} / \mathrm{ml})$, etoposide (VP-16) (0.075-0.6 $\mu \mathrm{M})$, and doxorubicin (0.015-0.07 $\mu \mathrm{g} / \mathrm{ml})$. The number of cells were adjusted to obtain 2000-3000 colonies in the control dishes. After 21 days the colonies were counted as previously described (Jensen et al, 1993).

\section{Animal Experiments}

Six- to eight-week-old female nu/nu-META/Bom (Bomholtgaard, Ry, Denmark) nude mice were used in all experiments and housed in the animal facility in laminar flow clean benches at $25^{\circ} \mathrm{C}$ and $50 \%$ humidity and maintained according to the regulations set forth by the Danish Animal Experiments Inspectorate. For all tumor experiments, cells were harvested from subconfluent $(70-80 \%)$ monolayer cultures by scraping with a rubber policeman. The cell suspension $\left(10 \times 10^{6} \mathrm{cells} / \mathrm{ml}\right.$ in PBS) was inoculated $\left(2 \times 10^{6} \mathrm{cells} /\right.$ site) subcutaneously and bilaterally into the abdominal flanks of the recipient mice. Tumors were measured by perpendicular diameters, and tumor volumes were estimated by calculation using the formula 0.5 (width $^{2}$ $\times$ length).

Anti-tumor experiment. Thirty-three mice were inoculated with MDA-MB-231 BAG cells $\left(2 \times 10^{6}\right.$ cells $/$ site $)$ subcutaneously and bilaterally into the abdominal flanks. After 3 weeks of MDA-MB-231 BAG tumor growth, the mice were randomized for intravenous treatment with a single injection of either $5 \mathrm{mg} / \mathrm{kg}$ doxorubicin ( $1 \mathrm{mg} / \mathrm{ml}, n=16$ mice) or vehicle (isotonic $\mathrm{NaCl}, n=17$ mice) in the lateral tail vein. Tumor growth was monitored for an additional 16 days, and blood samples were drawn and the mice were sacrificed.

At the time of blood collection, mice were anaesthetized and blood was taken by cardiac puncture. Cold trisodium citrate ( 0.1 volume) was added immediately to give a final concentration of $12.9 \mathrm{~mm}$ citrate, and the sample was mixed by inversion. The plasma was separated from blood cells within 1 hour by centrifugation at $2000 \times g$ for 30 minutes at $4^{\circ} \mathrm{C}$, and 
the supernatant was stored frozen at $-80^{\circ} \mathrm{C}$ prior to assay.

\section{Statistical Analyses}

The strength of the association between tumor volume and plasma $\beta$-galactosidase was tested with the nonparametric Spearman's rank test, whereas the strength of the association between assay signal and either conditioned medium or standard curves for purified $\beta$-galactosidase in buffer/plasma/culture medium were tested with simple linear correlation. The results for tumor volume and plasma $\beta$-galactosidase in the treatment experiment were tested with the nonparametric Mann-Whitney $U$ test. The significance level was set to $5 \%$.

\section{References}

Astoul P, Colt HG, Wang X, Boutin C, and Hoffman RM (1994). "Patient-like" nude mouse metastatic model of advanced human pleural cancer. J Cell Biochem 56:9-15.

Brünner N, Thompson EW, Spang-Thomsen M, Rygaard J, Danø K, and Zwiebel JA (1992). lacZ transduced human breast cancer xenografts as an in vivo model for the study of invasion and metastasis. Eur J Cancer 28A:1989-1995.

Hoffman RM (1994). Orthotopic is orthodox: why are orthotopic-transplant metastatic models different from all other models? J Cell Biochem 56:1-3.

Holst-Hansen C, Brünner N, Johannessen BE, Felding J, and Stephens RW (1998). A new immunocapture assay for Escherichia coli beta-galactosidase for in vivo studies of lacZtransduced tumor cells. Lab Invest 78:1643-1644.

Holst-Hansen C, Johannessen B, Høyer-Hansen G, Rømer J, Ellis V, and Brünner N (1996). Urokinase-type plasminogen activation in three human breast cancer cell lines correlates with their in vitro invasiveness. Clin Exp Metastasis 14:297-307.
Jensen PB, Christensen IJ, Sehested M, Hansen $\mathrm{HH}$, and Vindeløv L (1993). Differential cytotoxicity of 19 anticancer agents in wild type and etoposide resistant small cell lung cancer cell lines. $\mathrm{Br} \mathrm{J}$ Cancer 67:311-320.

Lin WC, Pretlow TP, Pretlow TG II, and Culp LA (1990). Bacterial lacZ gene as a highly sensitive marker to detect micrometastasis formation during tumor progression. Cancer Res 50:2808-2817.

Low JA, Johnson MD, Bone EA, and Dickson RB (1996). The matrix metalloproteinase inhibitor batimastat (BB-94) retards human breast cancer solid tumor growth but not ascites formation in nude mice. Clin Cancer Res 2:1207-1214.

Pocard M, Tsukui H, Salmon RJ, Dutrillaux B, and Poupon MF (1996). Efficiency of orthotopic xenograft models for human colon cancers. In Vivo 10:463-469.

Price J, Turner D, and Cepko C (1987). Lineage analysis in the vertebrate nervous system by retrovirus-mediated gene transfer. Proc Natl Acad Sci U S A 84:156-160.

Roed H, Christensen IB, Vindelov LL, Spang-Thomsen M, and Hansen $\mathrm{HH}$ (1987). Inter-experiment variation and dependence on culture conditions in assaying the chemosensitivity of human small cell lung cancer cell lines. Eur $\mathrm{J}$ Cancer Clin Oncol 23:177-186.

Will C, Wilhelm O, Hohl S, Mobus V, Weidle U, Kreienberg R, Janicke F, Schmitt M, and Graeff H (1975). Expression of urokinase-type plasminogen activator (UPA) and its receptor (UPAR) in human ovarian cancer cells and in vitro invasion capacity. Int J Oncol 5:753-761. 